\title{
Damage-free structures of green copper nitrite reductase obtained by neutron crystallography and XFEL
}

\author{
S. Antonyuk \\ Molecular Biophysics Group, ISMIB, Faculty of Health and Life Sciences; University of Liverpool, UK \\ S.Antonyuk@liverpool.ac.uk
}

Copper-containing nitrite reductases (CuNiRs) that convert $\mathrm{NO}_{2}$ to $\mathrm{NO}$ are of central importance in nitrogen-based energy metabolism [1]. These metalloenzymes, like all redox enzymes, are very susceptible to radiation damage from the intense synchrotron radiation by $\mathrm{X}$-rays, that are used to obtain structures at high resolution. Understanding the chemistry that underpins the enzyme mechanisms in these systems usually requires atomic resolutions of better than $1.2 \AA$. The damage-free structure of the resting state of one of the most studied CuNiRs was obtained by X-ray free-electron laser (XFEL) and neutron crystallography, which allows direct comparison of neutron, XFEL structural data [2] and atomic resolution X-ray structural data used to obtain the most accurate (atomic resolution with unrestrained SHELX refinement) structure.

It was demonstrated that $\operatorname{Asp}_{\mathrm{CAT}}\left(\mathrm{Asp}_{98}\right)$ and $\operatorname{His}_{\mathrm{CAT}}\left(\mathrm{His}_{255}\right)$ are deprotonated in the resting state of $\mathrm{CuNiRs}$ at $\mathrm{pH}$ values close to the optimum for activity (Fig.1).

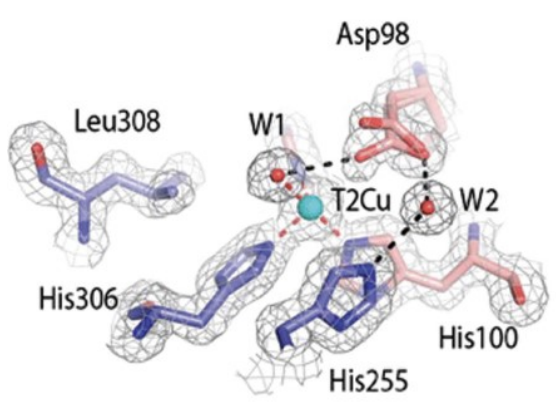

(a)

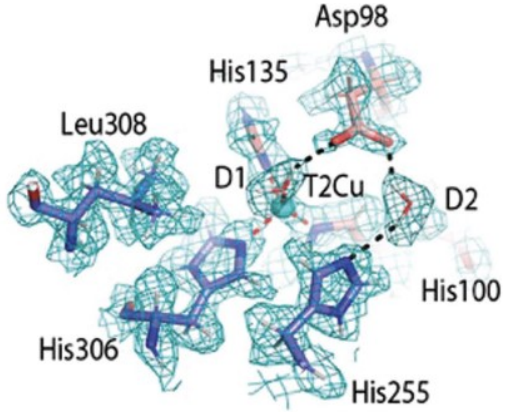

(b)

Figure 1. The T2Cu site of AcNiR determined by SF-ROX (a) and neutron crystallography (b).

[1] Zumft, W. G. (1997). Microbiol. Mol. Biol. Rev. 61, 533

[2] Halsted, T.P., Yamashita, K., Gopalasingam, C. C., Shenoy, R.T, Hirata, K., Ago, H., Ueno, G., Blakeley, M.P., Eady, R R.; Antonyuk, S.V., Yamamoto, M., Hasnain, S. S. (2019). IUCrJ 6, 761

Keywords: copper-containing nitrite reductases; neutron crystallography; X-ray free-electron lasers

Acknowledgement; Moulin M.; Haertlain,M.; Blakeley, M.P.; Halsted, T.P.; Yamashita, K.; Gopalasingam, C,;: C.;Hirata, K; Ago, H.; Ueno, G.; Eady, R R.; Yamamoto, M. and Hasnain S.S 